\title{
In-depth study of the microstructure of bamboo fibres and their relation to the mechanical properties
}

Journal of Reinforced Plastics and

Composites

$0(0)$ I-15

(C) The Author(s) 2018

Reprints and permissions:

sagepub.co.uk/journalsPermissions.nav DOI: $10.1177 / 0731684418783055$ journals.sagepub.com/home/jrp

@SAGE

\author{
L Osorio', E Trujillo', F Lens², J Ivens', I Verpoest' and \\ AW Van Vuure'
}

\begin{abstract}
The mechanical properties of bamboo technical fibre, from the species Guadua angustifolia, have been studied showing values of strength up to $800 \mathrm{MPa}$ and E-modulus up to $43 \mathrm{GPa}$, proving their adequate tensile properties that make this natural fibre suitable as reinforcement in composite materials. To fully explore the good mechanical properties and to make an adequate use of this new reinforcement, it is indispensable to comprehensively understand the fibre behaviour as a function of the microstructure. Microscopic observations have provided us with an extensive knowledge of the complex microstructure of this natural fibre from the macroscale down to the microscale level where different features like the distribution of the elementary fibres within the fibre bundle, dimensions and layering pattern of the elementary fibres and the main microfibrillar angles could be measured. The Young's modulus of the elementary fibre is analysed based on the micromechanics of composite materials, commonly used for unidirectional short fibre composites, and the fibre microstructure. The predicted results are in reasonable agreement with experimental data, showing the appropriateness of the model for describing the elementary fibre stiffness. Also, the failure modes of single fibres after tensile testing are analysed by microscopic observations, to have an indication of the stress development in the elementary fibres and the different failure mechanisms.
\end{abstract}

\section{Keywords}

Bamboo fibres, natural fibres, bamboo fibre composites, micromechanics of composites

\section{Introduction}

Bamboo fibres are an attractive alternative to reinforced polymers in the new era of green composite materials. ${ }^{1}$ Bamboo is an effective plant in terms of global warming prevention. It releases $35 \%$ more oxygen and sequesters four times more $\mathrm{CO}_{2}$ per hectare and per year $\left(60 \mathrm{t} \mathrm{CO}_{2} /\right.$ ha y) than a young tropical forest. ${ }^{2}$

In spite of the well-known usefulness of this plant, its fibres which are the main structural component in the culms have been scarcely used on a large scale due to the difficulty in extracting high quality technical fibres. In the current research project, a mechanical process has been developed to extract long bamboo technical fibres from Colombian grown Guadua angustifolia with the aim of using them as reinforcement in composite materials, as an alternative to glass fibres.

In previous studies, ${ }^{1,3}$ fibre mechanical properties were studied to determine the fibre quality after the extraction process and the mechanical performance of the new material. The tensile strength has a small variation as a function of the test span length and is about $800 \mathrm{MPa}$. The Young's modulus is on average $43 \mathrm{GPa}$. In terms of specific properties, normalized to the density, these properties can be compared with glass fibre. ${ }^{4}$ Bamboo fibre composites were also produced and tested to verify the performance of the fibres as reinforcement of polymeric matrices. Especially in epoxy

\footnotetext{
'Department of Metallurgy and Materials Engineering, KU Leuven, Heverlee, Belgium

${ }^{2}$ Netherlands Centre for Biodiversity Naturalis - section NHN, Leiden, The Netherlands

Corresponding author:

L Osorio, Department of Metallurgy and Materials Engineering, KU Leuven, Kasteelpark Arenberg 44 bus 2450, Heverlee 300I, Belgium. Email: linarocio.osorioserna@kuleuven.be
} 
resin, there was a good transfer of fibre properties into composite properties, with unidirectional (UD) composite strength reaching $80 \%$ of the theoretical strength with untreated fibres. 1,5

In this paper, microstructural and mechanical characteristics of bamboo fibres from the species G. angustifolia are studied at the meso and micro level, with special emphasis on the elementary fibre and its layered nature.

First, microstructural observations of natural and bamboo fibres are summarized. Second, a complete characterization of bamboo fibres is carried out going from the meso to the micro level by using different microscopic techniques, as a first approach to explain the behaviour of the technical fibre, used as reinforcement in composite materials. Finally, a novel approach is proposed to estimate the Young's modulus of the elementary fibre, by combining the micromechanics of composite materials and the fibre microstructure. Experimental results are shown to validate the predicted values together with an analysis of the fracture mechanisms of bamboo fibres to understand and predict their performance as reinforcement.

\section{Natural fibre microstructure}

The microstructure of natural fibres is extremely complex due to the hierarchical organization at different length scales and the different materials present in variable proportions. Elementary fibres are themselves composites; they consist of rigid cellulose microfibrils embedded in a soft lignin and hemicellulose matrix. Mechanical properties of plant fibres, especially strength and stiffness, are fully adapted to their function in the plant and depend on various factors such as cellulose content and microfibrillar angle (MFA). Based on this analogy, composites theory can be used to understand for example, the contribution of the angle of the cellulose microfibrils (reinforcing elements) on the fibre stiffness. ${ }^{6,7}$ When aligned, the microfibrils are more capable of carrying loads. The microfibril angle is then proportional with the impact resistance of the fibre and inversely proportional with both the strength and the stiffness of the fibre. ${ }^{8,9}$

As an example, the coconut is surrounded by a shell that contains the coir fibres and is designed to protect the nut against impact when it falls. Impact resistance typically means a high MFA.

On the other hand, flax and hemp fibres are both located in the stem of the plant and act as support against bending and buckling; low MFA is to be expected.

Table 1 summarizes the microstructure and some physical and mechanical characteristics of the elementary fibres of the most representative natural fibres currently used as reinforcement in composite materials.

A fibre bundle or a technical natural fibre is a group of elementary fibres that are glued together by amorphous material called middle lamellae. The technical fibres are generally obtained after an extraction process and can be used as such to reinforce polymers.

\section{Bamboo fibre microstructure}

The bamboo species used in this project is Guadua angustifolia, the economically most important bamboo species of the Western Hemisphere. In countries of the South, this plant has high perspective of industrial exploitation thanks to its large size, environmental benefits and availability.

The remarkable performance of bamboo and its fibres can be explained from its microstructure and has attracted the attention of many researchers. Throughout evolution, bamboos have developed a structurally intelligent plant: the fibres are oriented along the bamboo's culm, whereas in the nodes the fibres become entangled in a complicated manner to produce nodes with isotropic properties that provide additional reinforcement to the culm. ${ }^{23,24}$

At the macro level the bamboo culm can be seen as a typical UD fibre reinforced composite with the fibres as the reinforcing phase and the supporting tissue (parenchyma) as the matrix material. Shao et al. ${ }^{24}$ have successfully used the rule of mixtures, a simple model to describe aligned continuous fibre composites, to characterize the bamboo structure. The tensile strength and Young's modulus of fibre and parenchymatous tissue were estimated as $581 \mathrm{MPa}$ and $40 \mathrm{GPa}$ versus $19 \mathrm{MPa}$ and $0.2 \mathrm{GPa}$, respectively.

At the meso-level, in the cross-section of the bamboo culm wall, the fibre bundles that form a protecting sheath around the vascular bundles are distributed densely in the outer region of the wall and sparsely in the inner region, and are more concentrated in the upper part of the culm compared with the base, ${ }^{1,21}$ this has also a positive influence on the mechanical properties of the culm.

Tan et al. $^{25}$ have measured the Young's modulus through the cross-section of the culm of Moso bamboo, using nanoindentation techniques together with microtensile testing on bamboo slices. Stiffness and tensile strength decrease from the periphery of the bamboo wall towards the inner part, ranging from 13 to $7 \mathrm{GPa}$ and from 700 to $250 \mathrm{MPa}$, respectively.

The bamboo fibres: The micro level. Like other natural fibres, the technical bamboo fibre is a bundle of 
Table I. Physical and mechanical characteristics of some elementary fibres of natural fibres currently used as reinforcement in composite materials. $^{10-22}$

\begin{tabular}{|c|c|c|c|c|c|c|}
\hline \multirow[b]{2}{*}{ Natural fibre } & \multirow[b]{2}{*}{ Microstructure } & \multicolumn{5}{|c|}{ Elementary fibre characteristics and properties } \\
\hline & & $\begin{array}{l}\text { Length } \\
(\mathrm{mm})\end{array}$ & $\begin{array}{l}\text { Diameter } \\
(\mu \mathrm{m})\end{array}$ & MFA $\left({ }^{\circ}\right)$ & $\begin{array}{l}\text { Tensile strength } \\
(\mathrm{MPa})\end{array}$ & $\begin{array}{l}\text { Tensile modulus } \\
\text { (GPa) }\end{array}$ \\
\hline Flax fibre & & $4-140$ & $2-76$ & $5-10$ & $700-1250$ & $45-70$ \\
\hline Hemp fibres & & $8-55$ & $3-51$ & $2-6$ & $630-780$ & $19-44$ \\
\hline Sisal & & $1-8$ & $4-47$ & 22 & NA & NA \\
\hline Coir & & $0.4-1.2$ & $7-18$ & $30-49$ & NA & NA \\
\hline Bamboo (Moso) & & $\mathrm{I}-2.5$ & $10-23$ & $2-10$ & NA & NA \\
\hline
\end{tabular}

MFA: microfibrillar angle.

elementary fibres that are glued together by middle lamellae. The elementary fibres are aligned and have the shape of tube-like cells with thickened cell walls composed generally of four different layers surrounding a central lumen. Each layer consists generally of semicrystalline cellulose microfibrils embedded in a hemicellulose/lignin matrix at a defined angle. ${ }^{26}$ The layers are divided into two groups, namely the primary and secondary wall. The primary wall, the outermost layer, represents about $8 \%$ of the total thickness. The secondary wall is the thickest layer composing $80 \%$ of the total thickness and contributes the most to the mechanical properties. In this region the microfibrils are spirally wound around the lumen with a certain MFA.

The structure of the bamboo elementary fibre walls is unique and does not exist in the cell walls of fibres of normal wood and it is referred to as polylamellate 
Journal of Reinforced Plastics and Composites 0(0)

structure. ${ }^{21}$ This complex structure is composed of several thick and thin layers of lignin reinforced with cellulose microfibrils having different orientations. ${ }^{27,28} \mathrm{In}$ the thick wall layers, the cellulose microfibrils are oriented at a small angle to the fibre axis, whereas the thin ones show mostly a more transverse orientation to the fibre axis. Different results have been reported about the number of lamellae. This can be partly attributed to the position of the fibre bundles, the relative location of the fibres within the bundles and the state of maturity of the fibres. The alternating lamellae lead to a high tensile strength of the fibres and the culm. ${ }^{29}$

Researchers have studied in detail the morphology of the elementary fibre wall as well as the development of the polylamellar structure. According to Murphy and Alvin $^{28}$ and Gritsch and Murphy ${ }^{30}$ the multilayered structure does not show a defined pattern or a relation with the thickness of the cell wall. Also, the number of layers varies between individual fibres. It appears that the polylamellation is influenced by the position in the fibre bundle and a majority of the fibres do not possess any obvious layering of their walls. The number of layers is bigger in fibres adjacent to either vascular elements or at the periphery of the fibre bundles. ${ }^{21,29-31}$ It has been found that the multilayered structure of fibre cell walls is formed mainly during the first year of growth and there is no significant overall increase in wall thickness of fibre and parenchyma cells of bamboo culms older than one year. $^{29,32}$

Bamboo elementary fibres are long, tapered at both ends and sometimes forked. Shorter and smaller fibres occur at the peripheral layer of the culm wall. The fibre length is positively and strongly correlated with fibre diameter, cell wall thickness (number of layers) and internode diameter, but not with the lumen diameter and internode length. For bamboos, the elementary fibre diameter varies between 11 and $19 \mu \mathrm{m}$, the lumen diameter between 2 and $4 \mu \mathrm{m}$ and the cell wall thickness between 4 and $6 \mu \mathrm{m} .{ }^{21}$ In the short fibre reinforced composites and pulping industry, the length-todiameter ratio plays an important role in processing and mechanical properties. ${ }^{33,34}$

The mechanical properties of elementary bamboo fibres have been scarcely studied due to the difficulty to isolate individual fibres and to perform tensile tests. However, Ren et al. ${ }^{35}$ have successfully tested elementary fibres form the species Dendrocalamus, using a microtester with a 'ball and socket' fibre gripping. Results showed that the age has a little effect on the mechanical properties; the average Young's modulus and tensile strength were 43 and $1.6 \mathrm{GPa}$, respectively. Following the same methodology $\mathrm{Yu}$ et $\mathrm{al}^{36}$ have tested elementary fibres from 11 bamboo species from China. Similar results were found and the average values were $36.7 \mathrm{GPa}$ for Young's modulus and $1.55 \mathrm{GPa}$ for ultimate strength.

\section{Methodology}

Fibre microstructure

Culm samples were collected from two bamboo plantations in Colombia. The first one is the Center for the study of Bamboo-Guadua in Quindío - Colombia, located at $1240 \mathrm{~m}$ above sea level (a.s.1.) and with an average temperature of $25^{\circ} \mathrm{C}$. The second one is a typical bamboo plantation in Manizales (Coffee Region of Colombia) at $1880 \mathrm{~m}$ a.s.l. and with an average temperature of $20^{\circ} \mathrm{C}$.

Scanning electron microscope (SEM) observations were made on transverse sections of the culm in order to investigate the distribution of the vascular bundles as well as the microstructure of the elementary fibre wall. Samples $\left(1 \mathrm{~cm}^{3}\right)$ were cut using a sledge microtome (Reichert, Vienna, Austria) to preserve all the surface features and to avoid artefacts that can appear after grinding or polishing techniques. After treating with a bleaching agent, the samples were rinsed and dehydrated in an ethanol series (50, 75 and finally 96\%), followed by gold coating and observed using a SEM, Philips XL 30 FEG.

Thin sections for light microscope (LM) observations were made to observe the layering structure of the wall of the elementary fibres. Small samples $\left(1 \mathrm{~mm}^{3}\right)$ were progressively infiltrated with LR white (LRW) resin as follows: 20, 40, 50, 60, 80 and 100\% $\mathrm{LRW} /$ ethanol for at least $48 \mathrm{~h}$ at each concentration under vacuum conditions. Sections $5 \mu \mathrm{m}$ thick were produced using a Microm HM360 automatic rotary microtome (Thermo Fisher Scientific, Walldorf, Germany). The detailed procedure can be found in Hamann et al. ${ }^{37}$ Observations were carried out with a LM Dialux 20 (Leitz, Wetzlar, Germany).

\section{Fibre dimensions}

For the determination of the elementary fibre dimensions (length and diameter), macerations were prepared according to Franklin. ${ }^{38}$ Small bamboo blocks were treated with acetic acid and hydrogen peroxide and heated at $60^{\circ} \mathrm{C}$ overnight. Samples were then rinsed and dehydrated in an ethanol series and then coloured with safranin $1 \%$. The fibres were finally mounted on slides using heated Kaiser's glycerine. The bamboo culm wall was divided into three sections: 150 fibres were measured at three different positions over the width of the wall, outer, middle and inner part. LM observations were carried out with a Dialux 20 (Leitz, 
Wetzlar, Germany). Fibre dimensions were measured with the Digimizer image analyzer software.

\section{Microfibril angle}

The angle of the microfibrils in the primary and secondary layer of bamboo elementary fibres was determined based on a technique developed in Wang. ${ }^{39}$ First, the bamboo fibres were treated with copper nitrate solution $10 \%$ and heated at $80^{\circ} \mathrm{C}$ for $24 \mathrm{~h}$ and then placed into an ultrasonic bath at $60^{\circ} \mathrm{C}$ for $6 \mathrm{~h}$, in order to etch away some surface material. The treated bamboo fibres were finally washed with distilled water. The fibres were observed with a SEM Philips XL 30 FEG.

\section{Mechanical properties}

Single fibre tensile tests were done following the methodology described in Osorio et al. ${ }^{1}$ Gauge lengths of $0.5,1$ and $2 \mathrm{~mm}$ were chosen. The tensile tests were performed at the Department of Metallurgy and Materials Engineering, K.U. Leuven, Belgium on a TA Instruments Q800 Dynamic Mechanical Analyser, with a film tension clamp. The crosshead speed was set at $0.1 \mathrm{~mm} / \mathrm{min}$ and a $200 \mathrm{~N}$ load cell was used. The load and the displacement of the clamps were registered during the complete test. The equilibrium moisture content of bamboo technical fibres is $6.0 \pm 0.5 \%$ at $47 \mathrm{RH}$ and $21^{\circ} \mathrm{C}$ (experimental conditions). ${ }^{40}$

The shear lag theory. To correlate the fibre microstructure with the mechanical properties, a novel approach based on the micromechanics of composite materials is proposed. The technical bamboo fibre is considered as a UD short fibre composite (SFC), where the fibres are the elementary fibres. The elastic modulus of technical bamboo fibre is predicted based on two analytical models commonly used for SFC.

Also known as the Cox model, ${ }^{41}$ the shear lag theory is one of the first analytical models to describe the behaviour of SFC. This model assumes that the reinforcing fibres are aligned, encased in a concentric cylindrical shell of matrix and packed in an orderly manner. When loaded, the stress is transferred between fibres without yielding or slip. The longitudinal modulus of the composite $\left(\mathrm{E}_{\mathrm{c}}\right)$ can be calculated with the following equations $^{42}$

$$
\begin{gathered}
E_{c}=E_{F}\left(1-\frac{\tanh \left(\frac{\eta \mathrm{L}}{2}\right)}{\frac{\eta \mathrm{L}}{2}}\right) \mathrm{V}_{\mathrm{F}}+\mathrm{E}_{\mathrm{m}} \mathrm{V}_{\mathrm{m}} \\
\eta=\frac{1}{r}\left(\frac{2 E_{m}}{E_{f}\left(1+v_{m}\right) \ln \left(\frac{P_{f}}{V_{f}}\right)}\right)^{1 / 2}
\end{gathered}
$$

$\eta$ is a length-dependent efficiency factor, $r$ is the radius of the elementary fibre, $v_{m}$ is the Poisson's ratio of the matrix and $P_{f}$ refers to the packing factor and depends on the type of fibre packing that is assumed. For a hexagonal packing it is found: $P_{f}=2 \pi / \sqrt{3} .42,43$

Knowing that $E_{c}$ is the composite modulus, i.e. the technical fibre modulus, experimentally determined through tensile testing, ${ }^{1} E_{F}$, the fibre modulus, i.e. elementary fibre modulus can be back calculated as follows (equation (3))

$$
E_{f}=\frac{E_{c}-E_{m} V_{m}}{\left(1-\frac{\tanh \left(\frac{\eta L}{2}\right)}{\frac{\eta L}{2}}\right) V_{f}}
$$

$L$ is the elementary fibre length, $V_{F}$ is the elementary fibre volume fraction, $E_{m}$ is the modulus of the matrix material (lignin) and $V_{m}$ is the matrix volume fraction.

The Halpin-Tsai equations. In the Halpin-Tsai model a set of semi-empirical equations has been developed to predict the elastic properties of SFC. ${ }^{44}$ As in the Cox model, the fibres are assumed to be transversely isotropic and linear elastic. Inside the composite the fibres are perfectly aligned and well bonded at their interface (no interfacial slip). The longitudinal composite modulus can be calculated with the following equations ${ }^{45,46}$

$$
\begin{gathered}
E_{c}=E_{m}\left(\frac{1+\xi \eta V_{f}}{1-\eta V_{f}}\right) \\
\eta=\frac{\left(\frac{E_{f}}{E_{m}}\right)-1}{\left(\frac{E_{f}}{E_{m}}\right)+\xi}
\end{gathered}
$$

$E_{f}$ the fibre modulus, i.e. elementary fibre modulus, was back calculated using the methodology described in the previous paragraphs.

$E_{m}$ is the modulus of the matrix material (lignin) and $V_{f}$ is the elementary fibre volume fraction. $\xi$ is a shapefitting parameter which takes into consideration the packing arrangement and the geometry of the reinforcing fibres. If the modulus in the fibre direction is calculated and the fibres are circular, then $\xi$ is given by equation (6), where $L$ is the elementary fibre length and $D$ is the elementary fibre diameter

$$
\xi=2\left(\frac{L}{D}\right)
$$




\section{Results and discussion: The hierarchical structure of bamboo fibres}

\section{The meso-level: The vascular bundles}

The bamboo plant is a natural composite composed of parenchyma tissue reinforced by vascular bundles. In all bamboos, the size, shape, number and concentration of vascular bundles vary from the periphery towards the inner section of the culm (Figure 1(a)).

Close to the periphery of the culm, the vascular bundles are small, numerous and concentrated, while in the middle section of the culm they are larger and more widely spaced (Figure 1(b) to (d)). ${ }^{21}$ In G. angustifolia, the composition is $51 \%$ parenchyma tissue, $40 \%$ fibre and $9 \%$ conducting cells. ${ }^{45}$

To characterize the fibre bundle is not only of great importance in taxonomic research, but also to the fibre processing, because the shape and size of the fibre bundle have a strong influence on the difficulty of extraction and the dimensions and quality of the extracted technical fibres, since upon extraction the bean-shaped bundle splits in different parts (Figure 1(e)).

\section{The microscopic level}

Elementary fibres. The elementary fibres represent the main structural component of the bamboo culm and they exhibit a hexagonal or pentagonal shape; the small hole in the centre of each elementary fibre is called lumen (Figure 1(f)).

As mentioned before, each elementary bamboo fibre wall possesses a unique multilayer configuration called polylamellate structure which contributes to the strength and modulus of the bamboo culm. The fibre lumen fraction (ratio of the lumen area to the fibre cross-section) is on average $4 \%$ and was calculated for both elementary fibres present in the periphery
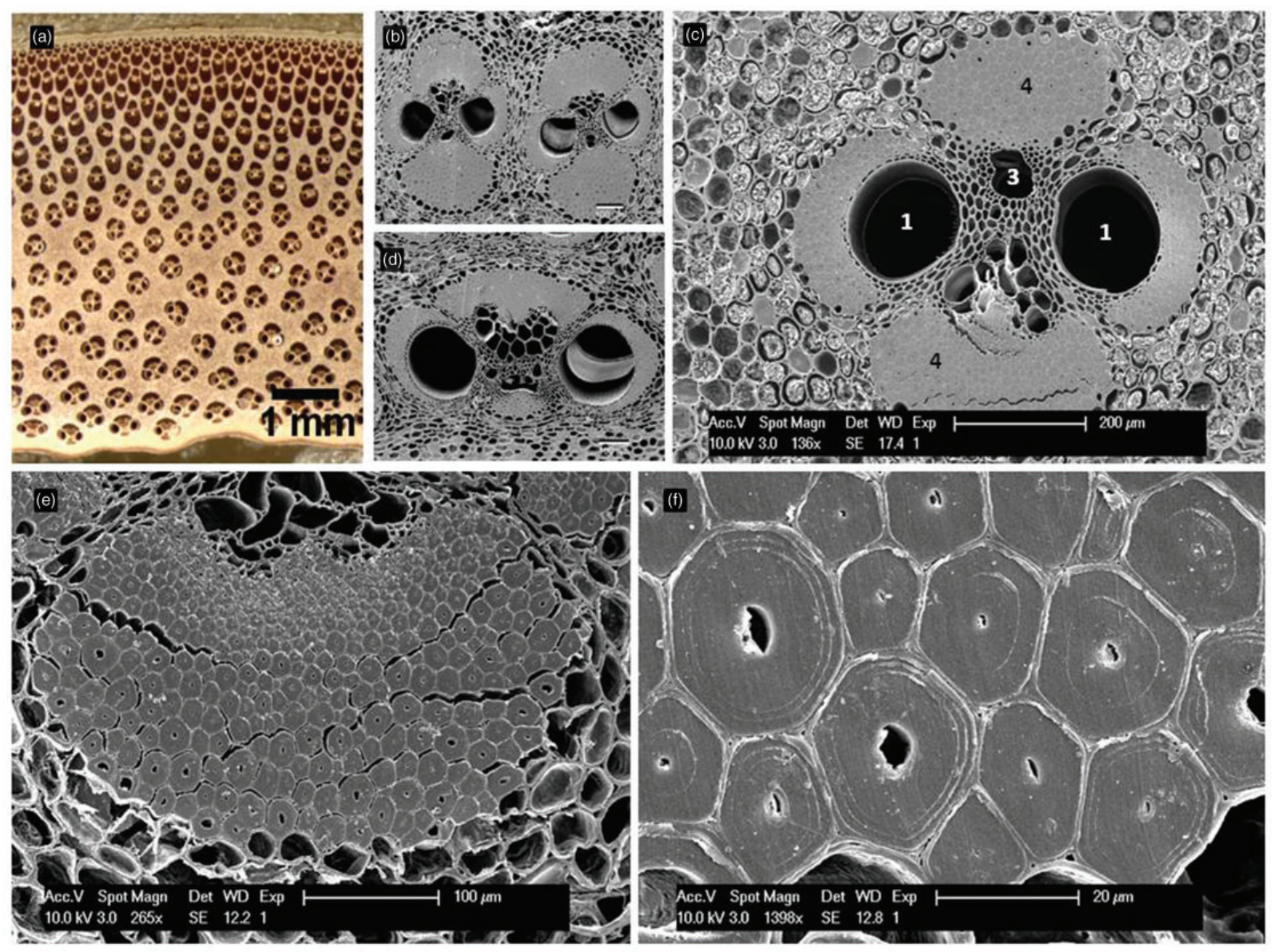

Figure I. (a) Distribution of vascular bundles in the bamboo wall (G. angustifolia). Morphology of the vascular bundles of G. angustifolia. (b) Outer, (c) middle and (d) inner section of the bamboo wall. Vascular bundle parts: vessels I, phloem 2, protoxylem 3, fibre bundles 4 and parenchyma tissue 5. (e) Bamboo fibre bundle; the bean-shaped bundle breaks up into a few technical fibres upon extraction. (f) Elementary bamboo fibres. 
(outer layer) and in the inner part (inner layer) of the fibre bundle (Figure 2).

As shown in Figure 1(e) and (f), the proportion of lumen tends to be higher towards the periphery of the

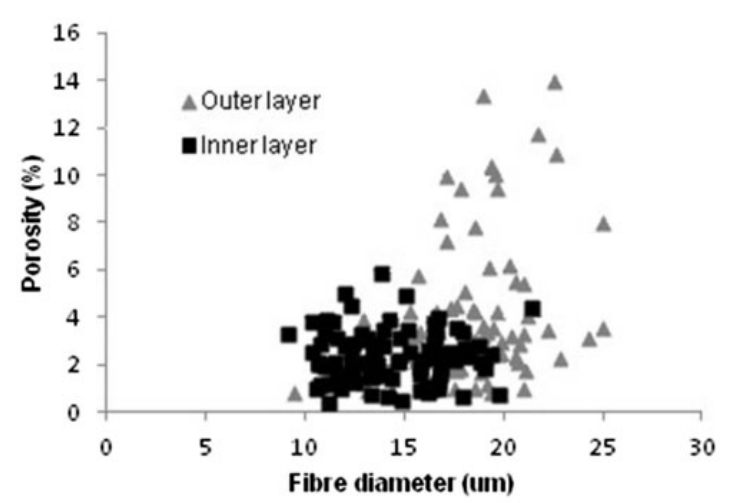

Figure 2. Lumen volume fraction in elementary fibres at two locations in the fibre bundle.

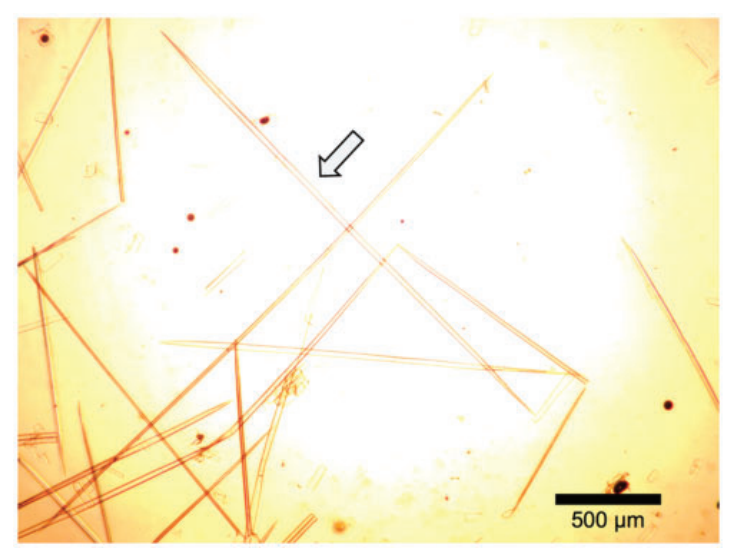

Figure 3. Elementary fibres after maceration. fibre bundle close to the parenchyma tissue which means that during the extraction process and the further refining of the fibre, it is desirable to remove part of these peripheral elementary fibres to reduce on one hand the technical fibre diameter and on the other hand the presence of big lumens which may lead to a high void content in the final composite. In the elementary fibres, the wall represents on average $96 \%$ of the total area. The middle lamella has a thickness of around $0.5 \mu \mathrm{m}$.

The elementary fibres are long and tapered at both ends (Figure 3). To measure the fibre length, the bamboo culm wall was divided into three sections (outer, middle and inner). The calculated mean elementary fibre length for G. angustifolia is $2.1 \pm 0.4 \mathrm{~mm}$.

Longer fibres are located in the outer and middle part of the culm, with an average length of $2.3 \pm 0.5$ and $2.3 \pm 0.4 \mathrm{~mm}$, respectively (Figure 4). This is also beneficial for the fibre extraction since these two regions have the higher percentage of fibre. The elementary fibre diameter varies from 10 to $25 \mu \mathrm{m}$; the distribution is shown in Figure 5.

Polylamellate structure of the elementary fibres. The secondary wall or the $\mathrm{S}_{2}$ layer forms the main portion $(\sim 80 \%)$ of the cell wall of the elementary fibres, being responsible for the mechanical performance of bamboo fibres. In agreement with other researches [6, 16-18], the polylamellate structure or multilayering of the elementary fibres for G. angustifolia is more visible in the periphery of the fibre bundle close to the parenchyma tissue and away from the vascular vessels. In general, elementary fibres in the outer zone have 2-4 layers and in some cases five layers were visible under LM (Figure 6(a) and (b)). Figure 6(c) shows an elementary fibre where there is not an obvious layering of the wall and this

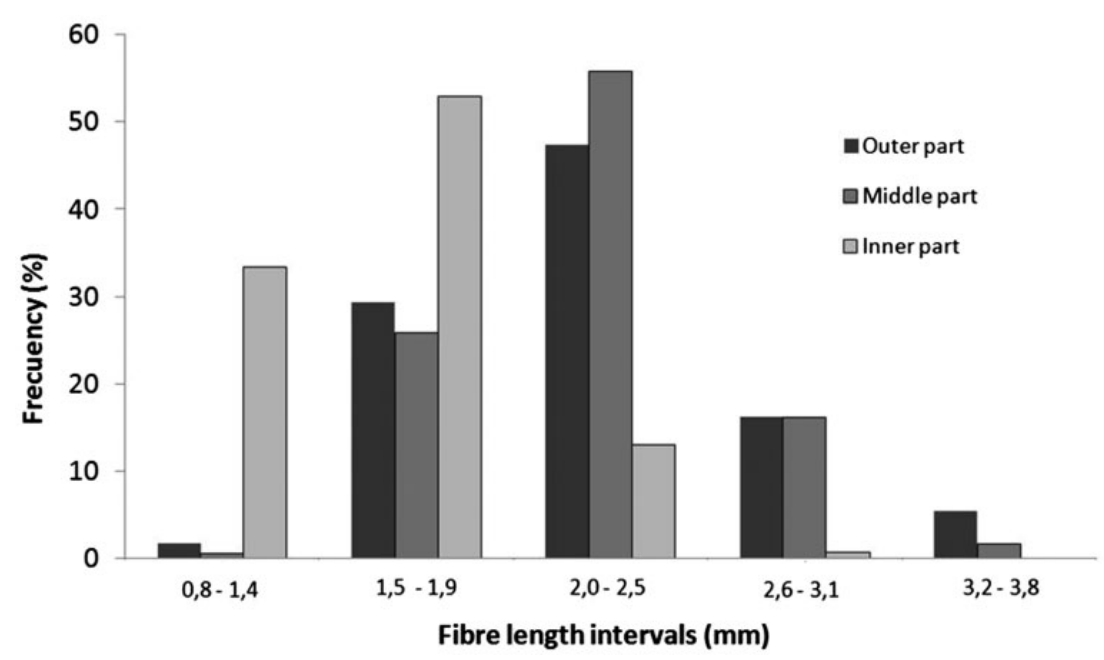

Figure 4. Elementary fibre length in three parts of the bamboo wall. 


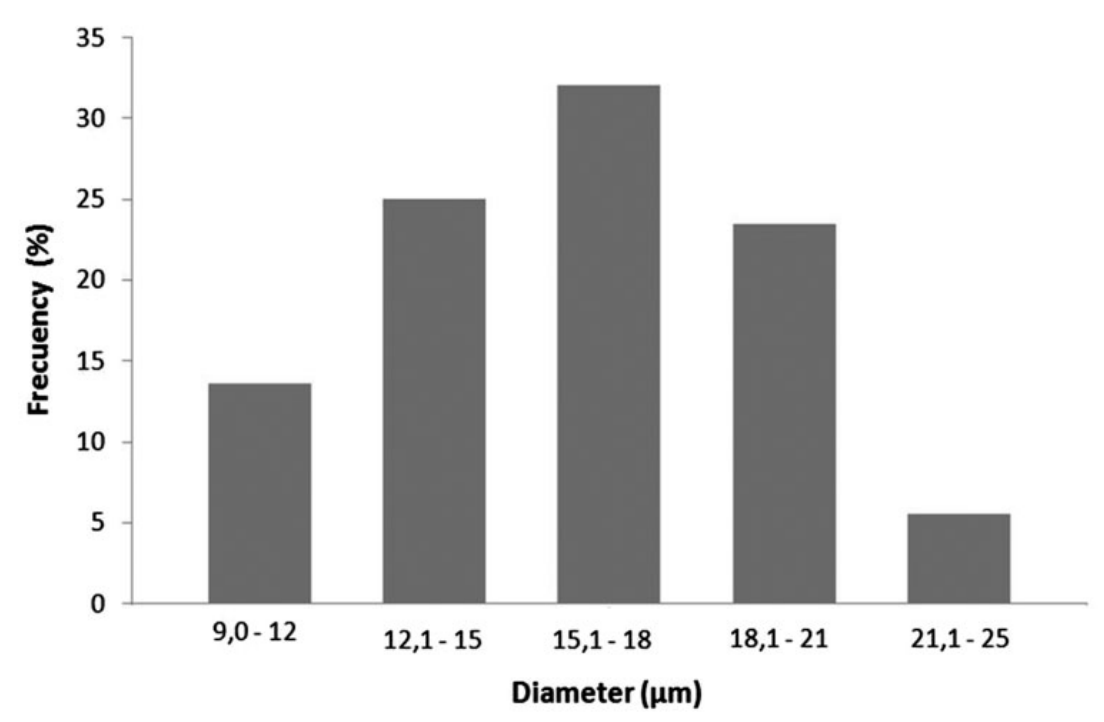

Figure 5. Elementary fibre diameter distribution.
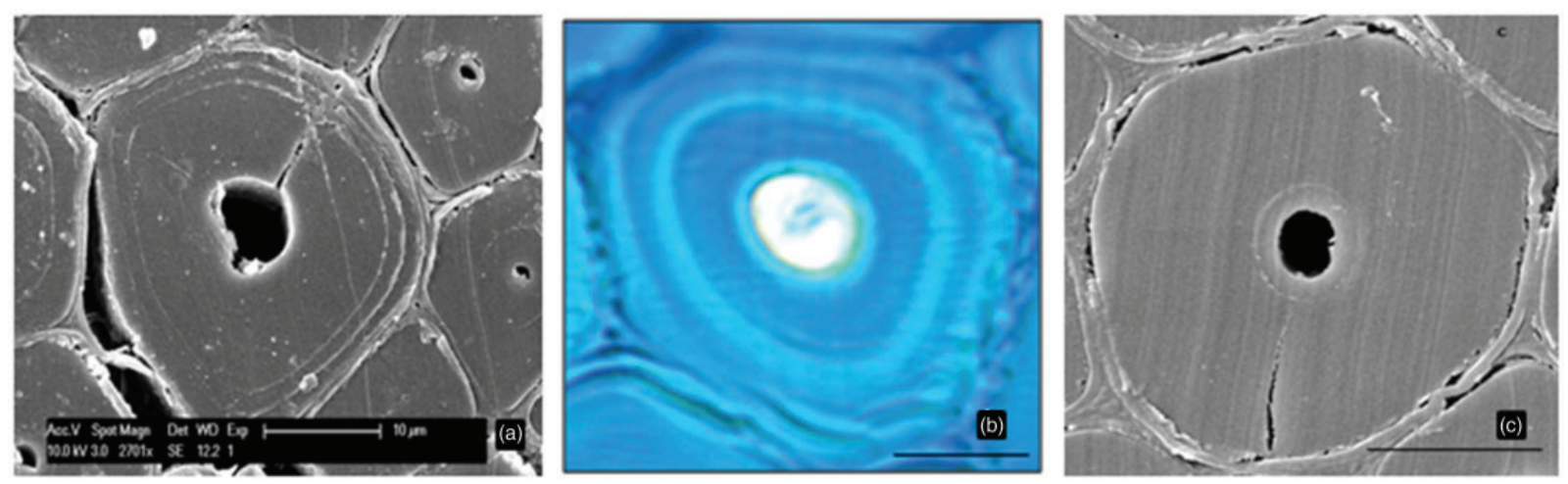

Figure 6. Polylamellate structure of elementary bamboo fibres: (a) Layering visible at the periphery of the fibre bundle, (b) layering visible under LM and (c) typical elementary fibre where layering is not visible. Scale bar $10 \mu \mathrm{m}$.

characteristic was predominant for the bulk of the observed elementary fibres.

MFA. Figure 7(a) shows a detail of the secondary wall of an elementary fibre, after the chemical treatment where the primary wall has been etched away. The orientation of the microfibrils is close to $0^{\circ}$ in agreement with Liese. ${ }^{21}$ The properties will be somewhat reduced due to the visible 'wavy' pathways of the microfibrils. Figure 7(b) shows a detail of the primary wall; the image is of a pulled-out elementary fibre at a fracture surface from a single fibre tensile test. The $90^{\circ}$ orientation of the microfibrils will provide some off-axis mechanical performance; this is evaluated in a followup paper.
Some elementary fibres at the periphery of the fibre bundle show a more multilayered structure being more prone to have different MFA. Figure 7(c) shows an elementary fibre with fibrils oriented at an angle of $\pm 30^{\circ}$; this sample was obtained from elementary fibres present in the outer layer of the fibre bundle close to the parenchyma tissue.

\section{Young's modulus of the elementary fibre}

By combining the microstructural analysis and the micromechanical models for SFC it is possible to back calculate the Young's modulus of the elementary fibre from the experimental data on technical bamboo fibres. 

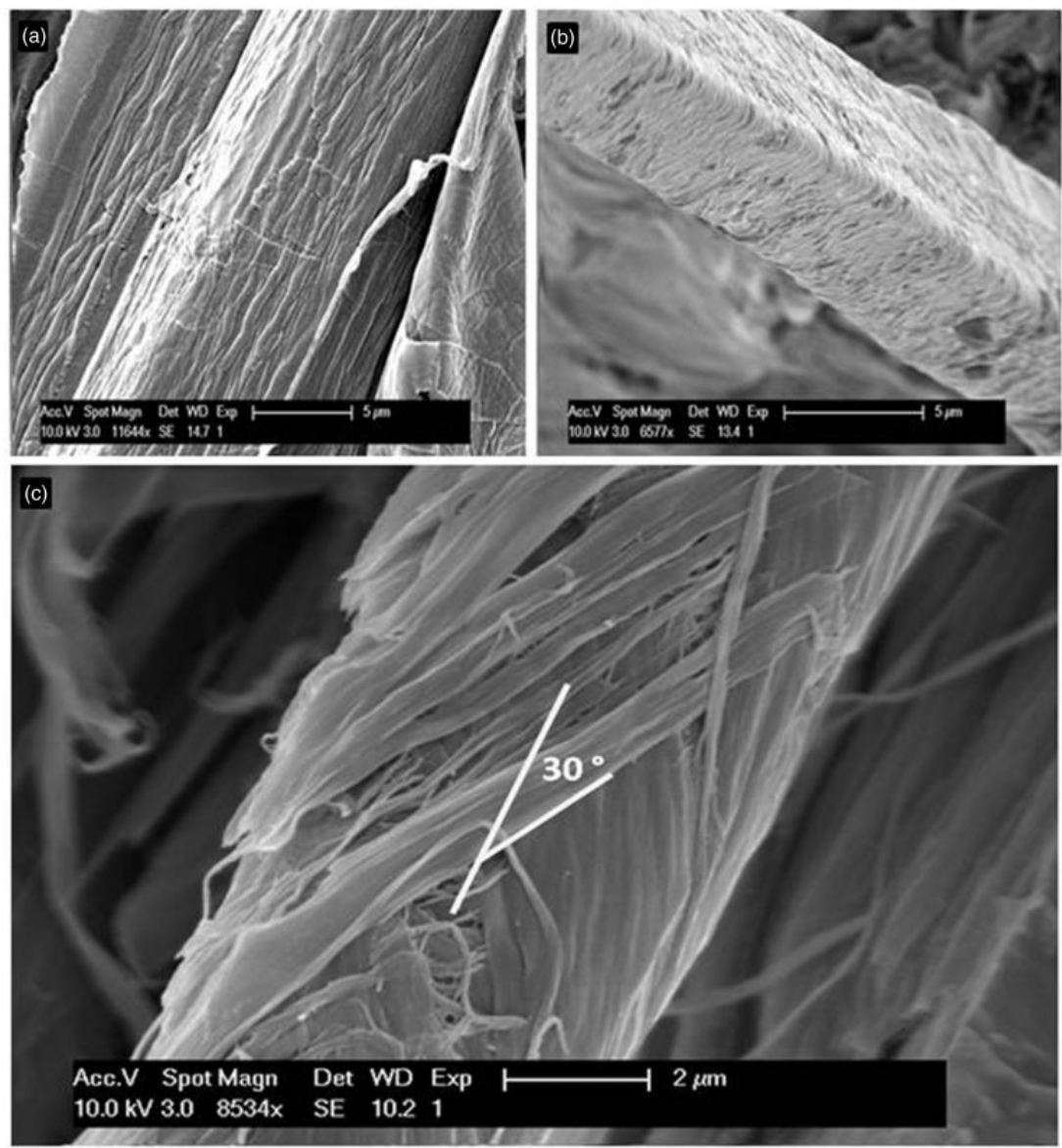

Figure 7. SEM images of elementary fibre microstructure: (a) secondary wall, (b) primary wall and (c) microfibrils oriented at an angle of $\sim \pm 30^{\circ}$.

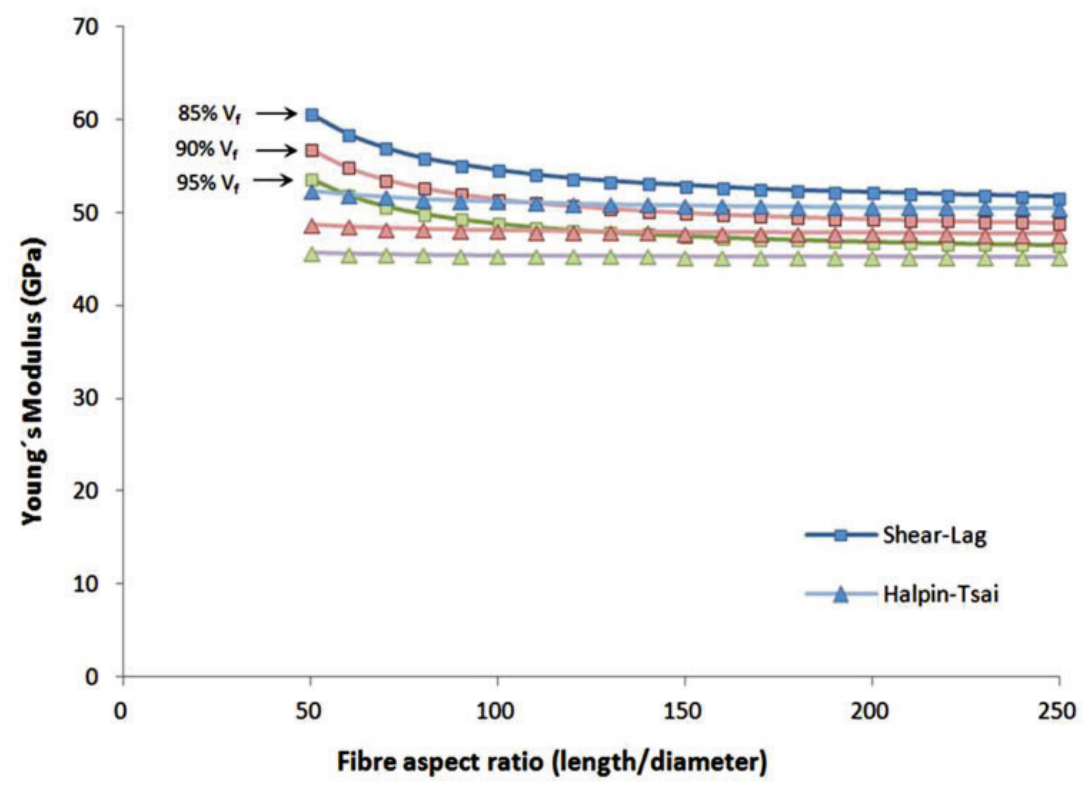

Figure 8. Estimated Young's modulus of elementary bamboo fibres at different fibre volume fractions $\left(V_{f}\right)$. 


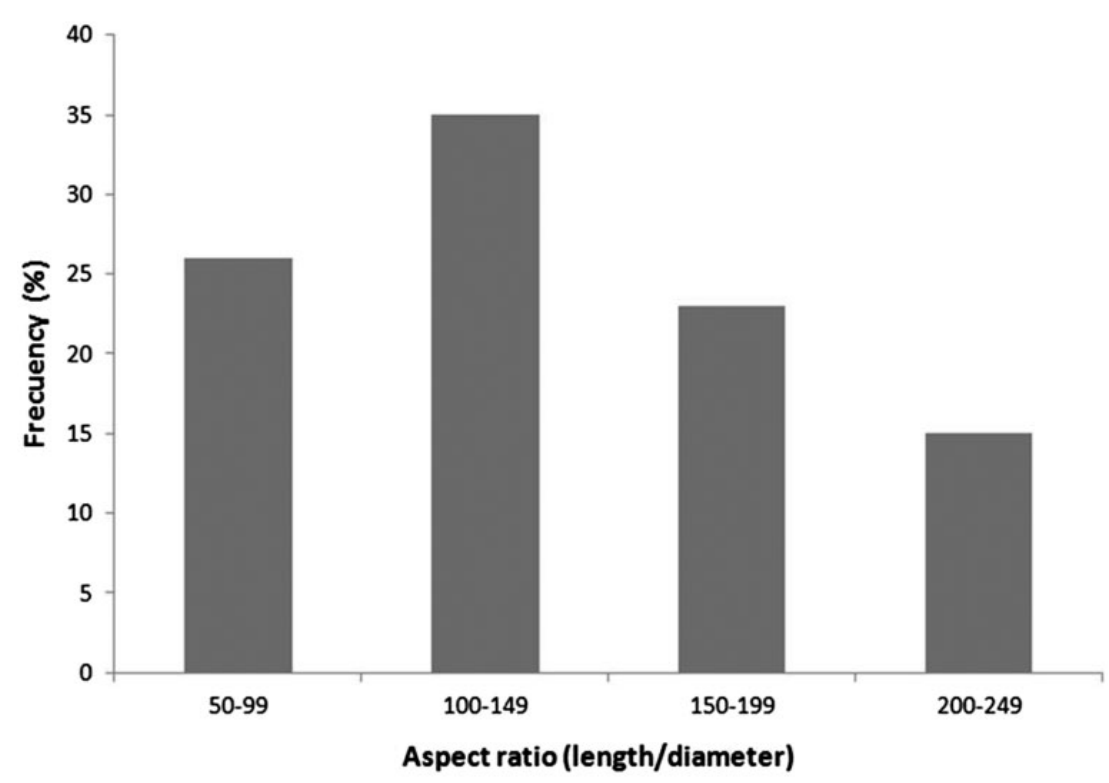

Figure 9. Distribution of aspect ratios (length/diameter) of elementary bamboo fibres.

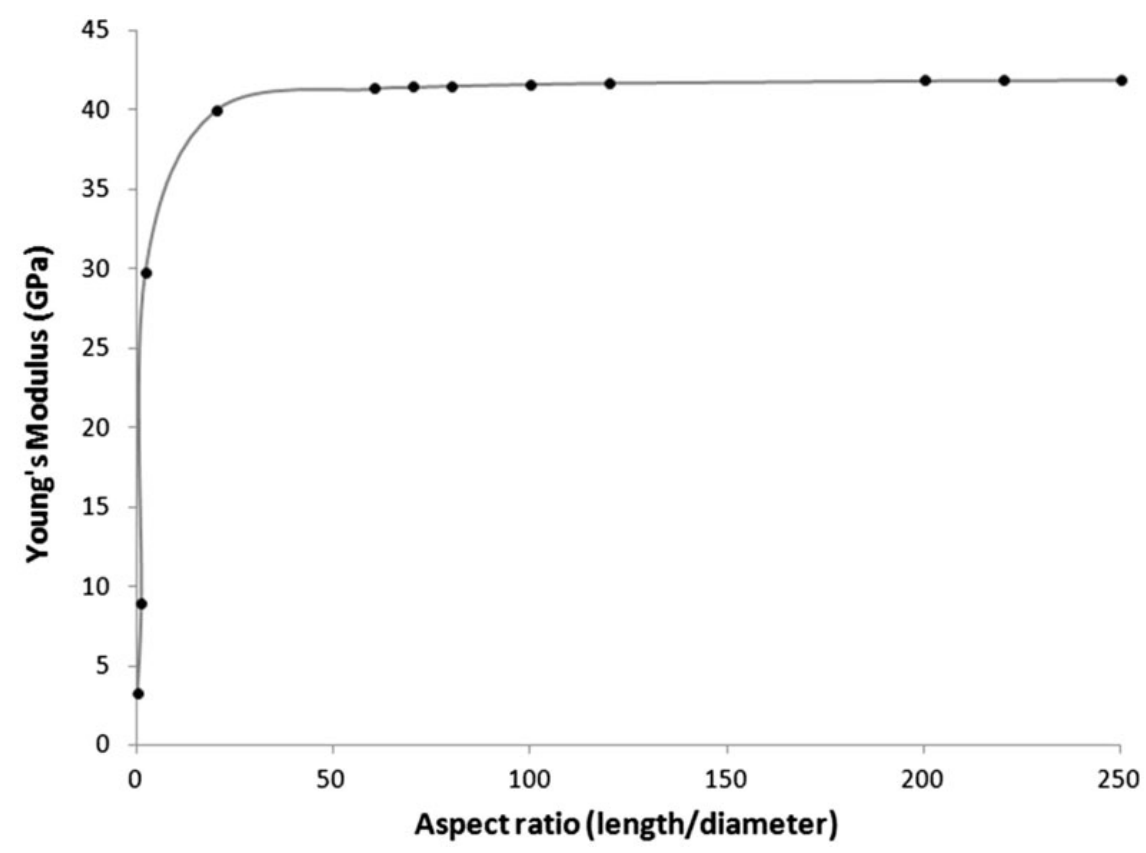

Figure 10. Effect of elementary fibre aspect ratio on the theoretical Young's modulus of the technical fibre. The aspect ratios of the elementary fibres vary from 70 to 200 .

A bamboo fibre has a hierarchical structure. On the first level, the technical fibre can be described as a discontinuous quasi-UD composite, consisting of elementary fibres in a lignin matrix. On the second level, the elementary fibre can be considered a concentric laminate, in which each layer has different properties. On the third level, each layer of the elementary fibre can be described again as a composite, consisting of oriented or random crystalline cellulose microfibrils, embedded in an amorphous matrix. In the micromechanical analysis, presented here, we focus on the first level, making abstraction of the internal (e.g. layered) microstructure of the elementary fibre, to calculate the properties of this elementary fibre, based on the tests performed on the technical fibres. The Young's modulus of the elementary fibre was back calculated with equations (3) and (4). 
The input parameters to back calculate $E_{f}$ were established as follows: Young's modulus of the technical fibre, $E_{c}=43 \mathrm{GPa},{ }^{1}$ Young's modulus of the lignin matrix, $E_{m}=3 \mathrm{GPa},{ }^{46} \mathrm{~L}$ : elementary fibre length
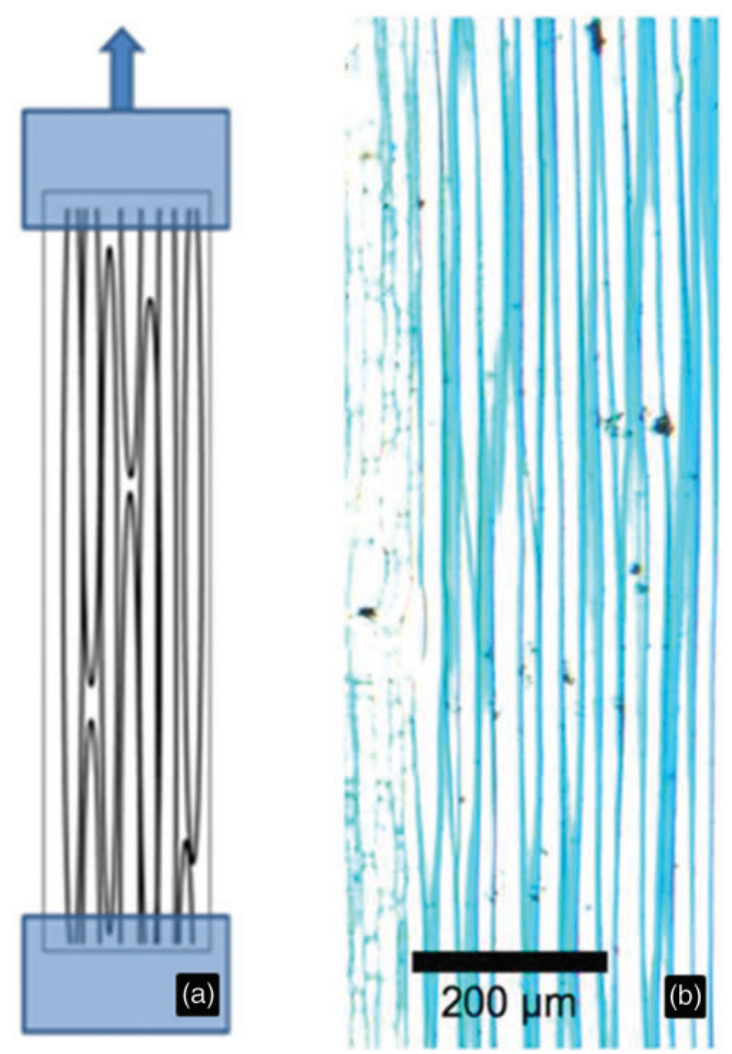

Figure I I. Tensile test set-up: (a) Schematic drawing of the UD distribution of the elementary fibre inside the technical fibres and (b) shows LM picture of a longitudinal cross-section of a technical fibre.
(Figure 4), D: elementary fibre diameter (Figure 5), $V_{f}$ : fibre volume fraction.

Based on the lumen fraction and the thickness of the lignin matrix connections, fibre volume fraction $\left(V_{f}\right)$ was calculated to be around $90 \%$. For $V_{f}=90 \%$, the estimated Young's modulus was on average 50.5 and $48 \mathrm{GPa}$ with the shear lag and the Halpin-Tsai models, respectively. As shown in Figure 8, for aspect ratios higher than 100, the models show little variation, especially for Halpin-Tsai.

The actual aspect ratio (length of the fibre/diameter) of the elementary fibres varies from 70 to 200 with a higher concentration in aspect ratios larger than 100 (Figure 9). Figure 10 shows the theoretical effect of the elementary fibre aspect ratio on the E-modulus of the technical fibre (for sufficiently long technical fibres), which is considered a composite. As observed in any discontinuous fibre composite, we see that low aspect ratios reduce the stiffness of the technical fibre, while with higher aspect ratios, the stiffness value of continuous fibres is reached. For the elementary fibre dimensions of the $G$. angustifolia, with an aspect ratio between 70 and 200, the stiffness values obtained from the discontinuous fibre model are identical to the continuous fibre model.

\section{Short span tensile test results of technical fibres}

Short span tensile tests were performed on technical fibres. The span lengths chosen for the test took into account the range of elementary fibre lengths, to assure that at least some elementary fibres were clamped in their entirety during the tensile test as shown schematically in Figure 11(a) and (b). The number of elementary fibres spanning the grips will increase with decreasing span length: at $2 \mathrm{~mm}$ span about $20 \%$ of

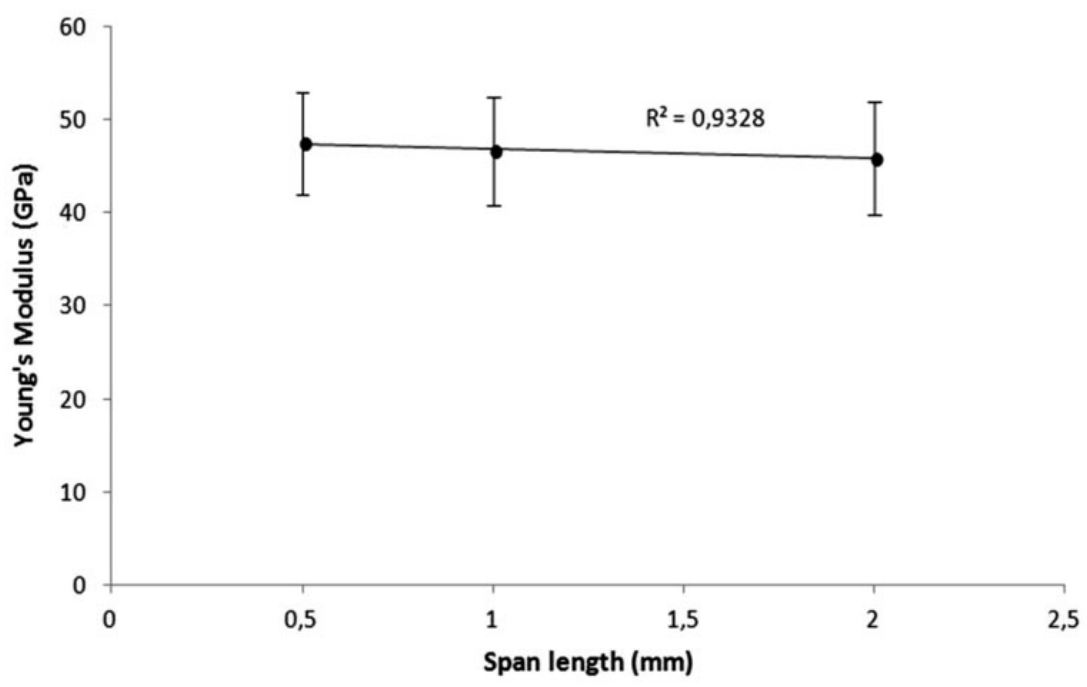

Figure 12. Young's modulus of technical bamboo fibres, experimental values. 

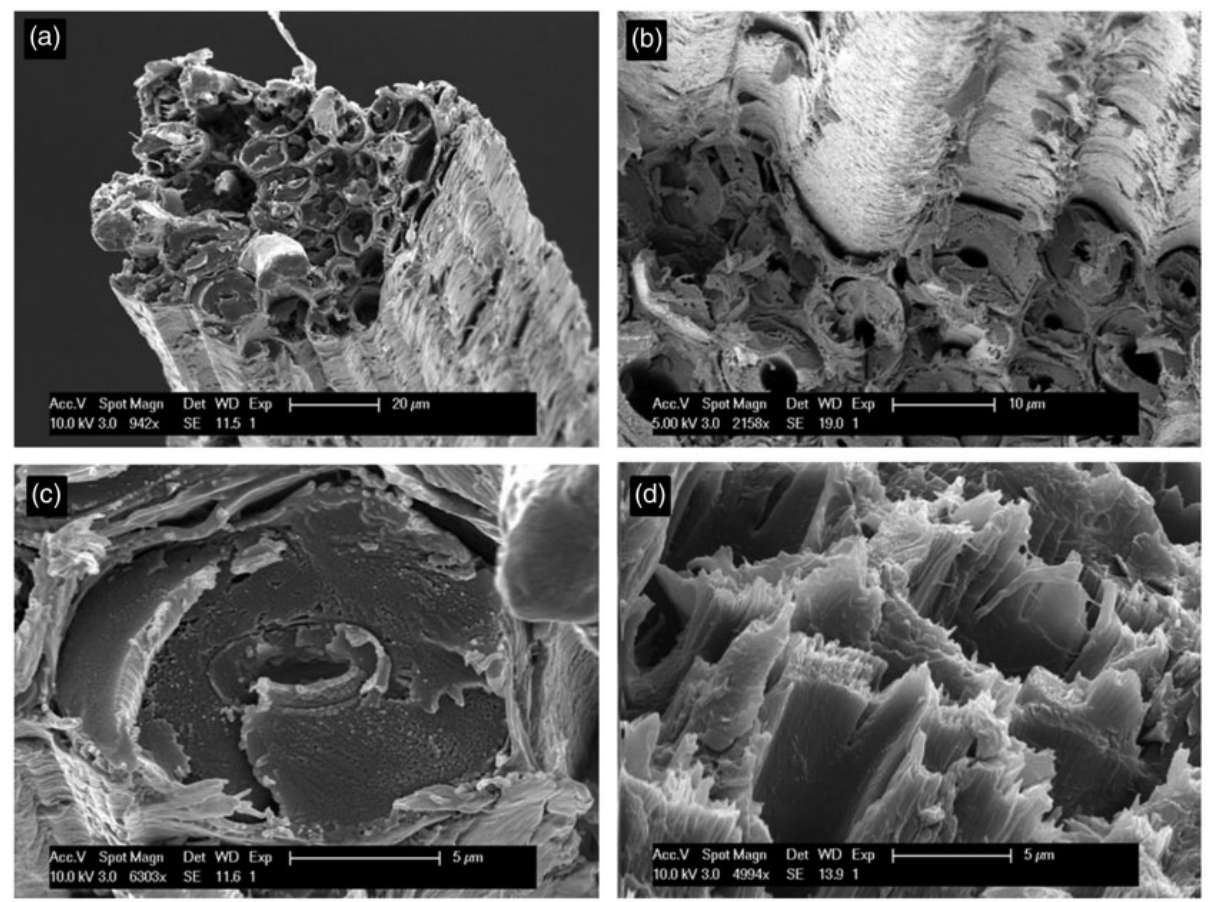

Figure 13. (a) Fracture surface of a technical fibre, (b) failure along the primary layer of elementary fibres, (c) elementary fibre with a thick secondary wall and (d) microfibrils of the secondary wall oriented at an angle of $0^{\circ}$.

\section{Morphological hierarchy in bamboo}

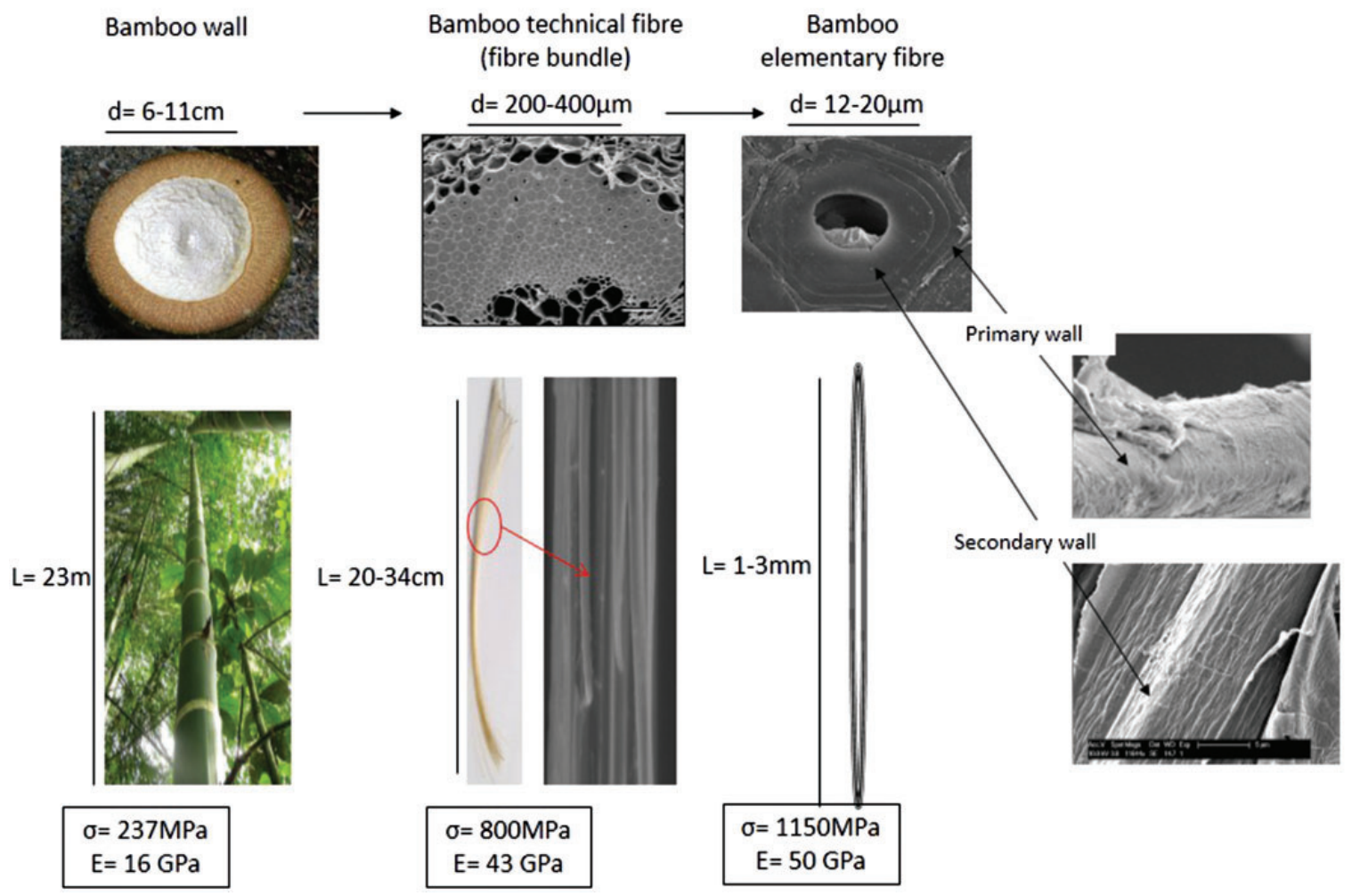

Figure 14. Morphological hierarchy in bamboo. 
the elementary fibres span the grips, at $1 \mathrm{~mm}$, this is $60 \%$ and at $0.5 \mathrm{~mm}$, this is $80 \%$ (for a $2.5 \mathrm{~mm}$ long elementary fibre). Bamboo technical fibre is therefore a (varying) combination of a discontinuous fibre composite and a continuous fibre composite. As the amount of continuous fibres increases, one would expect an increase in modulus with reduced span length. But applying Figure 10 to the actual elementary fibre dimensions shows that there is no difference, because the aspect ratio is such that even the discontinuous fibre model predicts a modulus identical to the continuous fibre model. Figure 12 shows the Young's modulus of the technical fibres at three different span lengths.

These results are in agreement with the predicted values. The orientation close to $0^{\circ}$ of the microfibrils of the secondary wall explains the high longitudinal stiffness of bamboo fibres. Nevertheless, the fibre properties are affected on one hand by the 'wavy' pattern of the microfibrils in the secondary wall, which is a natural characteristic of the microstructure and on the other hand, by the presence of some elementary fibre ends (Figure 11(a)) due to the sample conditions. Also in this test set-up zero slippage in the clamps was assumed. The effects of slippage and the presence of fibre ends will counteract each other: at short span there is relatively more slippage but less or no effect of fibre ends. All in all it is hypothesized that the actual modulus of the elementary fibres is higher than the $48 \mathrm{GPa}$ measured at short span and more likely close to the earlier calculated upper limit of $53 \mathrm{GPa}$ as back calculated from technical fibre modulus with the shear lag theory.

\section{Failure mechanisms}

Figure 13 shows a collection of different fracture surfaces after the single fibre tensile tests. Figure 13(a) shows a clean failure all through the technical fibre crosssection, indicating a good bonding between elementary fibres favouring the stress transfer between them.

In the failure mode of Figure 13(b) the technical fibre was split and the failure occurred along or inside the primary layer where the microfibrils are oriented at an angle of $90^{\circ}$. This result suggests that the primary layer would be weaker than the bonding material between elementary fibres (middle lamella consisting of lignin) or could point to adhesive failure at the interface between primary layer and lignin layer.

Figure 13(c) and (d) shows a more detailed view of a solid elementary fibre secondary wall. In Figure 13(d) the microfibrils of the secondary wall are visible and oriented in the direction of the fibre axis.

\section{Conclusions}

Microstructural observations reveal that the cellulose microfibrils of the elementary fibres have predominantly $0^{\circ}$ orientation in the main secondary wall, combined with an outer (primary wall) layer of $90^{\circ}$.

The hierarchical structure of bamboo fibres can be described with the help of the micromechanics of composite materials. As stated in literature, at the macro level, the bamboo culm is a perfect natural UD composite that can be described by the rule of mixtures.

At the micro level, the technical fibre represents a perfect UD SFC that can be described by means of the Cox model or the Halpin-Tsai semi-empirical equation. This means that the elementary fibres are perfectly aligned and well bonded to the matrix material without interfacial slip or debonding. The elementary fibre appears to have a Young's modulus of around $50 \mathrm{GPa}$, which is both found by back calculating from technical fibre modulus and experimentally by conducting very short span single fibre tensile tests.

In agreement with previous studies, the number of wall layers in the elementary fibres of the bamboo species $G$. angustifolia is higher at the periphery of the fibre bundle close to the parenchyma tissue. Also, a great heterogeneity was found in the measurements of fibre length and fibre diameter. Nevertheless, the measured aspect ratios (length/diameter) are larger than 70 .

Figure 14 summarizes the morphological hierarchy in bamboo. The length and diameter of the technical fibres guarantee a suitable aspect ratio which is an important factor for a reinforcing material. Also, the high elementary fibre content within the technical fibre bundle assures that more than $80 \%$ of the modulus of the elementary fibres is transferred to the technical fibre after the extraction process.

\section{Declaration of conflicting interests}

The author(s) declared no potential conflicts of interest with respect to the research, authorship, and/or publication of this article.

\section{Funding}

The author(s) disclosed receipt of the following financial support for the research, authorship, and/or publication of this article: This research was sponsored by the Belgian Science Policy Office (BELSPO), in a cooperative project with Vietnam.

\section{References}

1. Osorio L, Trujillo E, Van Vuure AW, et al. Morphological aspects and mechanical properties of single bamboo fibers and flexural characterization of bamboo/epoxy composites. J Reinf Plast Compos 2011; 30: 396-408. 
2. Janssen J. Designing and building with bamboo. Eindhoven: Technical University of Eindhoven, 2000.

3. Trujillo E, Moesen M, Osorio L, et al. Bamboo fibres for reinforcement in composite materials: strength Weibull analysis. Compos Part A Appl Sci Manuf 2014; 61: 115-125.

4. Trujillo E, Osorio L, Fuentes C, et al. (eds). Bamboo fiber thermoplastic for transport applications. In: $S A M P E$ Europe 31 international technical conference and forum 2010, Paris, France, 2010.

5. Trujillo D and Los RE. Polymer composite materials based on bamboo fibres. Leuven: KU Leuven, 2014.

6. Bledzki AK and Gassan J. Composites reinforced with cellulose based fibres. Prog Polym Sci 1999; 24: 221-274.

7. Kaw AK. Mechanics of composite materials. CRC Press, 2005.

8. Baillie C. Green composites: polymer composites and the environment. CRC Press, 2004.

9. Liese W. Anatomy and properties of bamboo. Recent Research on Bamboos. In: Proceedings of the International Bamboo Workshop, 6-14 October 1985, Hangzhou, People's Republic of China.

10. Gourier C, Le Duigou A, Bourmaud A, et al. Mechanical analysis of elementary flax fibre tensile properties after different thermal cycles. Compos Part A Appl Sci Manuf 2014; 64: 159-166.

11. Baley C. Analysis of the flax fibres tensile behaviour and analysis of the tensile stiffness increase. Compos Part $A$ Appl Sci Manuf 2002; 33: 939-948.

12. Charlet K. Tensile deformation of a flax fiber. Procedia Eng 2009; 1: 233.

13. Charlet K, Jernot J-P, Breard J, et al. Scattering of morphological and mechanical properties of flax fibres. Ind Crops Products 2010; 32: 220-224.

14. Placet V. Characterization of the thermo-mechanical behaviour of hemp fibres intended for the manufacturing of high performance composites. Compos Part A Appl Sci Manuf 2009; 40: 1111-1118.

15. Placet V, Trivaudey F, Cisse O, et al. Diameter dependence of the apparent tensile modulus of hemp fibres: a morphological, structural or ultrastructural effect? Compos Part A Appl Sci Manuf 2012; 43: 275-287.

16. Fidelis MEA, Pereira TVC, Gomes dFM, et al. The effect of fiber morphology on the tensile strength of natural fibers. J Mater Res Technol 2013; 2: 149-157.

17. Oksman K, Mathew AP, Langstrom R, et al. The influence of fibre microstructure on fibre breakage and mechanical properties of natural fibre reinforced polypropylene. Compos Sci Technol 2009; 69: 1847-1853.

18. de Andrade Silva F, Chawla N and de Toledo Filho RD. Tensile behavior of high performance natural (sisal) fibers. Compos Sci Technol 2008; 68: 3438-3443.

19. Tran L, Minh TN, Fuentes C, et al. Investigation of microstructure and tensile properties of porous natural coir fibre for use in composite materials. Ind Crops Products 2015; 65: 437-445.
20. Verpoest I, Baets J, Acker J, et al. Flax and hemp fibres: a natural solution for the composite industry. Paris: JEC Composites, 2012.

21. Liese W. The anatomy of bamboo culms. Technical Report. International Network for Bamboo and Rattan, 1998.

22. Wang F, Shao J, Keer LM, et al. The effect of elementary fibre variability on bamboo fibre strength. Mater Des 2015; 75: 136-142.

23. Amada S. Fiber texture and mechanical graded structure of bamboo. Compos Part B Eng 1997; 28: 13.

24. Shao Z-P, Fang C-H, Huang S-X, et al. Tensile properties of Moso bamboo (Phyllostachys pubescens) and its components with respect to its fiber-reinforced composite structure. Wood Sci Technol 2009; 44: 655-666.

25. Tan T, Rahbar N, Allameh S, et al. Mechanical properties of functionally graded hierarchical bamboo structures. Acta Biomater 2011; 7: 3796-3803.

26. Mohanty AK, Misra M and Drzal LT. Natural fibers, biopolymers, and biocomposites. CRC Press, 2005.

27. Parameswaran $\mathrm{N}$ and Liese W. On the fine structure of bamboo fibres. Wood Sci Technol 1976; 10: 231-246.

28. Murphy $\mathrm{R}$ and Alvin K. Variation in fiber wall structure in bamboo. IAWA Bull 1992; 13: 403-410.

29. Gritsch CS. Developmental changes in cell wall structure of phloem fibres of the bamboo Dendrocalamus asper. Ann Bot 2004; 94: 497.

30. Gritsch CS and Murphy RJ. Ultrastructure of fibre and parenchyma cell walls during early stages of culm development in Dendrocalamus asper. Ann Bot 2005; 95: 619-629.

31. Lybeer B, Van Acker $\mathbf{J}$ and Goetghebeur P. Variability in fibre and parenchyma cell walls of temperate and tropical bamboo culms of different ages. Wood Sci Technol 2006; 40: 477-492.

32. Lybeer B, Koch G, Van Acker J, et al. Lignification and cell wall thickening in nodes of Phyllostachys viridiglaucescens and Phyllostachys nigra. Ann Bot 2006; 97: 529-539.

33. Liese W and Grosser D. Untersuchungen zur Variabilität der Faserlänge bei bambus. Holzforsch Holzverwert 1972; 26: 202-210.

34. Rajulu AV, Baksh SA, Reddy GR, et al. Chemical resistance and tensile properties of short bamboo fiber reinforced epoxy composites. J Reinf Plast Compos 1998; 17: $1507-1511$.

35. Ren D, Yu Z, Li W, et al. The effect of ages on the tensile mechanical properties of elementary fibers extracted from two sympodial bamboo species. Ind Crops Products 2014; 62: 94-99.

36. Yu Y, Wang H, Lu F, et al. Bamboo fibers for composite applications: a mechanical and morphological investigation. J Mater Sci 2014; 49: 2559-2566.

37. Hamann T, Smets E and Lens F. A comparison of paraffin and resin-based techniques used in bark anatomy. Taxon 2011; 60: 841-851. 
38. Franklin G. Preparation of thin sections of synthetic resins and wood-resin composites, and a new macerating method for wood. Nature 1945; 155: 51.

39. Wang HH. An improved fibril angle measurement method for wood fibres. Wood Sci Technol 2001; 34: 493.

40. Osorio L, Trujillo E, Van Vuure AW, et al. Microstructural analysis and mechanical behaviour of bamboo fibres. In: ECCM15 - 15th European conference on composite materials, Venice, Italy, 2012.

41. Cox H. The elasticity and strength of paper and other fibrous materials. Br J Appl Phys 1952; 3: 72.

42. Facca AG. Predicting the elastic modulus of natural fibre reinforced thermoplastics. Compos Part A Appl Sci Manuf 2006; 37: 1660.
43. Tucker Iii CL. Stiffness predictions for unidirectional short-fiber composites: review and evaluation. Compos Sci Technol 1999; 59: 655.

44. Halpin $\mathbf{J}$ and Kardos J. The Halpin-Tsai equations: a review. Polym Eng Sci 1976; 16: 344-352.

45. Londoño X, Camayo G, Riaño N, et al. Characterization of the anatomy of Guadua angustifolia (Poaceae: Bambusoideae) culms. J Am Bamboo Soc 2002; 16: 18-31.

46. Cousins W, Armstrong R and Robinson W. Young's modulus of lignin from a continuous indentation test. J Mater Sci 1975; 10: 1655-1658. 